\title{
ORBITAL PSEUDOTUMOUR- THE OCULOMOTOR NERVE PALSY MIMICKER
}

\author{
Dinesh Kumar1, Shakeen Singh2, Anureet Gill33, Shubham Mahajan ${ }^{4}$
}

${ }_{1}^{1}$ Assistant Professor, Department of Medicine, SGRDIMSR, Amritsar, Punjab, India.

2 Professor and HOD, Department of Ophthalmology, SGRDIMSR, Amritsar, Punjab, India.

3Junior Resident, Department of Ophthalmology, SGRDIMSR, Amritsar, Punjab, India.

4Intern, Department of Medicine, SGRDIMSR, Amritsar, Punjab, India.

HOW TO CITE THIS ARTICLE: Kumar D, Singh S, Gill A, et al. Orbital pseudotumour - the oculomotor nerve palsy mimicker. J. Evolution Med. Dent. Sci. 2019;8(04):279-280, DOI: 10.14260/jemds/2019/60

\section{PRESENTATION OF CASE}

A 53-year old female patient, a known case of CA breast (Status post-mastectomy, on tamoxifen since last 2 years), presented to our Neurology OPD 1 month back with the chief complaint of double vision and very severe pain in left eye. Patient had a history of trivial trauma to the same eye one month prior to that by "some insect" hitting her eye while riding a two-wheeler. The pain was sudden in onset and was associated with severe headache. She was managed conservatively at an outside hospital and felt partly relieved by analgesics; but subsequently she developed diplopia within a period of 15 days. This was associated with pain and nasal field of vision defect of left eye.

Her past medical records from outside hospital documented visual acuity in right eye was normal while in left eye was $6 / 9$ pinhole $6 / 6 \mathrm{p}$. Intraocular pressure was 19 $\mathrm{mmHg}$ in right eye and $18 \mathrm{mmHg}$ in left eye. On fundus examination, disc was normal. Ocular movements were restricted (specifically adduction and elevation) and were consistent on diplopia charting. Conservative management continued at outside hospitals.

Over the next few days, she was not relieved of the pain in left eye; that was intermittent, sudden in onset and so severe in intensity that it was difficult for her to even keep her eyes open. This was associated with watering. Pain was mildly relieved with analgesics and such episodes used to last for two to three days. The severity and duration of pain increased over time, it was progressive and had started to impair her daily routine. She got ocular examination done at different facilities multiple times, but every time her visual acuity and intra-ocular pressure used to be normal or nearnormal. Gradually, conservative treatment ceased to provide her relief anymore. Most disabling of her symptoms now were eye pain, double vision and inability to see in up gaze, down gaze and towards the right (with left eye).

Recently she visited our Neurology OPD. After getting a detailed history, main findings on her clinical examination were mild proptosis in left eye, associated with slight chemosis, divergent squint 45 degrees and restricted extraocular movements (Elevation, depression and adduction). Levator palpebrae superioris muscle was functioning normally. Pupillary reactions (Both direct and indirect) were normal as well.

'Financial or Other Competing Interest': None.

Submission 13-12-2018, Peer Review 14-01-2019,

Acceptance 22-01-2019, Published 28-01-2019.

Corresponding Author:

Dinesh Kumar,

F7/29, Mata Kaulan Marg,

Uashmir Avenue, Amritsar, Punjab, India.

E-mail: manishksharma27@gmail.com

DOI: $10.14260 /$ jemds $/ 2019 / 60$

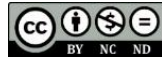

We referred her to the Department of Ophthalmology for an opinion. Thorough ocular examination was conducted there, and same findings were endorsed.

There were few points to ponder in the case. When a patient presents with extraocular movement restriction, before making a diagnosis of nerve palsy, other signs of particular nerve involvement should be looked for. Also associated signs and symptoms should not be ignored (In this case proptosis, chemosis and eye pain) which might not fit into initial diagnosis (Here oculomotor palsy) and hence should make us think about alternative diagnostic possibility (here orbital pseudotumour).

\section{CLINICAL DIAGNOSIS}

Orbital Pseudotumour (Idiopathic Orbital Inflammatory Syndrome).

\section{DIFFERENTIAL DIAGNOSIS}

1. Oculomotor Nerve Palsy.

2. Thyroid eye disease.

3. Orbital cellulitis.

4. Lymphoproliferative disease.

5. Metastatic disease.

6. Sarcoidosis.

7. Wegner's granulomatosis.

8. Tolosa Hunt Syndrome.

\section{PATHOLOGICAL DISCUSSION}

Her haematological tests, including thyroid function tests, were normal. After a comprehensive work up and based on the particular restricted extraocular movements, we initially diagnosed her as a case of oculomotor nerve palsy. But from a neurological viewpoint, there seemed to be something incomplete. Proptosis, though mild, still did not fit in. Forced Duction test was indeterminate. Given her atypical presentation, we got MRI of orbit with contrast done that revealed ill-defined mixed signal intensity lesion in the intraconal compartment of the left orbit involving Medial Rectus, Inferior Rectus and posterior part of the Superior Rectus muscles. PET scan was done that ruled out secondaries. Biopsy of left medial rectus belly was planned and done by the Ophthalmology Department. The histopathological examination showed muscle fibres with infiltration by inflammatory cells consisting of lymphocytes, plasma cells, macrophages and few neutrophils; without any evidence of malignancy.

Orbital pseudotumour are entities that often challenge ophthalmologists, neurologists and radiologists. Here, we presented an unusual case that mimicked oculomotor nerve palsy at initial presentation, but the pathology was Orbital Pseudotumour. Orbital myositis is one of the most common components of orbital pseudotumour and majority of cases 
are unilateral. ${ }^{1}$ Structures that might be involved in this process include eyeball, fat, extra ocular muscle, lacrimal gland, connective tissues, and optic nerve.2, 3 Hence the need to keep high clinical suspicion as this clinical entity can mimic a lot of common diagnoses. Cause of this disease entity is unknown (hence the term 'Idiopathic Orbital Inflammatory Syndrome'). Some of the known causes are trauma and surgical inflammation, immune-autoimmune condition and low-grade fibrosarcoma with inflammatory cells. ${ }^{4-6}$

Imaging studies should not be delayed if clinical suspicion is high. MRI is a valuable procedure of choice for the diagnosis of orbital pseudotumour. ${ }^{7}$ In our patient it was one of the key tools that helped clinch the diagnosis, other one being the histopathology report. Biopsy helps confirm the diagnosis, as it did in our case.

\section{DISCUSSION OF MANAGEMENT}

Particularly after histopathology report, our diagnostic suspicion shifted from oculomotor nerve palsy to restrictive pathology, likely orbital pseudotumour. This was further substantiated when we started her treatment with systemic prednisolone, to which she responded drastically over the next 3-5 days and there was significant relief in diplopia and in vision in up gaze and down gaze, but minimal improvement in adduction. We added mycophenolate mofetil and patient is showing gradual improvement with the current regimen of treatment. She is being closely followed up by our team in the Neurology and Ophthalmology Departments on a regular basis and we are content with the improvement in her condition at each successive visit, which would not have been possible if we did not keep a wide range of diagnostic suspicion.

Systemic corticosteroid therapy is the cornerstone of treatment of this condition. Improvement with corticosteroid treatment is of diagnostic importance; specifically, a corticosteroid responsive orbital process is more likely to correlate with pseudotumour. ${ }^{8}$ Other treatment options are immunosuppressants (Methotrexate, Cyclosporine, Azathioprine), chemotherapeutic agents, TNF-alpha inhibitors, mycophenolate mofetil and radiation therapy. Aim is to make correct diagnosis of this great mimicker without unnecessary delay so that appropriate treatment can be initiated in a timely manner to avoid restrictive myopathies that can lead to considerable visual morbidity to the patient otherwise.

\section{FINAL DIAGNOSIS}

Orbital Pseudotumour- Left Eye.

\section{REFERENCES}

[1] Keane JR. Alternating proptosis. A case report of acute orbital myositis defined by the computerized tomographic scan. Arch Neurol 1977;34(10):642-3.

[2] Yan J, Wu P. Idiopathic orbital myositis. J Craniofac Surg 2014;25(3):884-7.

[3] Schatz CJ. The orbit. In: Som PM, Bergeron RT, Curtin HD, et al. eds. Head and neck imaging. $2^{\text {nd }}$ edn. St. Louis: Mosby-Year Book 1991: p. 783-8.

[4] Narla LD, Newman B, Spottswood SS, et al. Inflammatory pseudotumour. Radiographics 2003;23(3):719-29.

[5] Maves CK, Johnson JF, Bove K, et al. Gastric inflammatory pseudotumour in children. Radiology 1989;173(2):381-3.

[6] Sanders BM, West KW, Gingalewski C, et al. Inflammatory pseudotumour of the alimentary tract: clinical and surgical experience. J Pediatr Surg 2001;36(1):169-73.

[7] Badr MA, Elkhamary SM, Al-Sabbagh S, et al. Bilateral optic nerve sheath meningioma with intracanalicular and intracranial component in a 25-year-old Saudi patient. Middle East Afr J Ophthalmol 2008;15(3):13841.

[8] Harris GJ. Idiopathic orbital inflammation: a pathogenetic construct and treatment strategy: The 2005 ASOPRS Foundation Lecture. Ophthal Plast Reconstr Surg 2006;22(2):79-86. 